\title{
A comprehensive study of the structure, tautomeric properties, and conformational flexibility of 3-Hydroxy-propeneselenal
}

\author{
MEHDI YOOSEFIAN ${ }^{\mathrm{a}, *}$, HEIDAR RAISSI ${ }^{\mathrm{b}}$ and SAEEDEH SOHEILI ${ }^{\mathrm{b}}$ \\ ${ }^{a}$ Department of Chemistry, Graduate University of Advanced Technology, Kerman, Iran \\ ${ }^{b}$ Department of Chemistry, University of Birjand, Birjand, Iran \\ e-mail: myoosefian@yahoo.com
}

MS received 28 March 2014; revised 05 December 2014; accepted 27 January 2015

\begin{abstract}
In the present work, a conformational analysis of 3-Hydroxy-propeneselenal is performed using several computational methods, including HF, DFT (B3LYP), and G2MP2 levels of theory. The relative electronic energies, the molecular structure, and intramolecular hydrogen bond energies are reported. Twenty different conformers were obtained, the most stable ones being planar. The conformational preference of this molecule was found to be mainly determined by the formation of Se...H-O and Se-H...O intramolecular hydrogen bonds, which are assisted by $\pi$-electron resonance. The atoms in molecules (AIM) theory of Bader, which is based on topological properties of the electron density, was used to analyze critical points and to study the nature of hydrogen bonds in these systems. NMR and natural bond orbital (NBO) analyses were also performed for a better understanding of the nature of intramolecular interactions in 3-Hydroxy-propeneselenal. Furthermore, calculations for all the possible conformations of the title compound in solution were also carried out at the B3LYP/6-311++G(d,p) level of theory (in three models such as polarizable continuum model (PCM), IEFPCM, and self-consistent isodensity polarized continuum model (SCIPCM).
\end{abstract}

Keywords. 3-Hydroxy-propeneselenal; conformational analysis; NMR; AIM and NBO analysis.

\section{Introduction}

Organoselenium chemistry is the science of exploring the properties and reactivity organoselenium compounds. ${ }^{1-4}$ Selenols (RSeH) are the selenium equivalents of alcohols and thiols. These compounds are relatively unstable and generally have unpleasant odour. Selenium, in the form of organoselenium compounds, is an essential micronutrient whose absence from the diet causes cardiac muscle and skeletal dysfunction. Many chemical processes are modulated by the existence or the formation of intramolecular hydrogen bonding (IMHB), and the formation of strong IMHB is behind the large basicity of many super-bases. ${ }^{5-12}$ The hydrogen bond is often described as an electrostatic dipoledipole interaction. However, it has some features of covalent bonding: It is directional, strong, produces interatomic distances shorter than the sum of van der Waals radii, and usually involved in a limited number of interactions.

3-Hydroxy-propeneselenal (HPS) is an interesting molecule that possesses two types of intramolecular

*For correspondence hydrogen bonds (HB), Se...H-O and Se-H...O. Theoretically, three classes of tautomers, namely, HP, SP and SOP, can be expected (figure 1). HPS has about 20 different plausible conformers that can be systematically arranged in three tautomeric classes, that is, HP, SP, SOP, which have 8, 8, 4 conformers, respectively. SP-1 and HP-1 conformers are stabilized by intermolecular hydrogen bond and are predominant in the gas phase and solution phase, respectively, where two atoms that behave as the proton donor and proton acceptor are highly electronegative. The main goal of this study is the prediction of the most stable structure among the plausible conformations and evaluation of the nature of intramolecular hydrogen bonding chelated forms by means of $a b$ initio and DFT calculations. Furthermore, in this study, a detailed population analysis for some of the most stable conformers of HPS was performed by natural bond orbital (NBO) ${ }^{13}$ and atoms in molecules $(\mathrm{AIM})^{14}$ methods. HPS in particular would be a very important goal to estimate the hydrogen bond strength of the Se...HO and SeH...O bridges. We have considered it also of interest to investigate the solvent effect on the relative stability of the most stable tautomers and predict the most stable structure in the gas phase and in solution. 


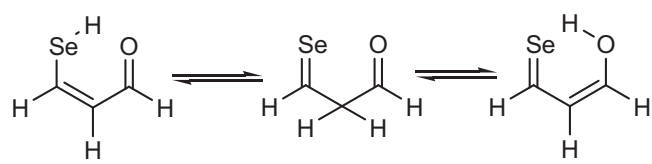

Figure 1. Tautomer equilibrium in HPS.

\section{Computational Methods}

$A b$ initio and DFT calculations were carried out using the Gaussian 03 program. ${ }^{15}$ The relative energies were calculated at the $\mathrm{B}^{2} \mathrm{LYP}^{16}$ and the extrapolated MP2 (including the second-order correlation corrections) ${ }^{17}$ methods with $6-311++\mathrm{G}(\mathrm{d}, \mathrm{p})$ basis set and G2MP2 theoretical level. Harmonic vibrational frequencies were estimated at the same levels to confirm the nature of the stationary points found and also to account for the zero point vibrational energy (ZPVE) correction. The nature of the intramolecular HB in 3-Hydroxypropeneselenal conformers has been studied using the AIM theory of Bader by means of AIM $2000^{18}$ software using the B3LYP/6-311++G(d,p) wave functions as input. NBO analysis ${ }^{19}$ at the same level of DFT theory was carried out to understand the orbital interactions and charge delocalization during the course of the reaction. The actual calculations were performed for water solution, which were modeled using the polarizable continuum model (PCM), IEFPCM, and self-consistent isodensity polarized continuum model (SCIPCM). ${ }^{20}$ The NMR absolute shielding constants ( $\sigma$ values) were calculated at the B3LYP/6-31++G(d,p) level with the gauge-independent atomic orbital (GIAO) method. $^{21}$ The calculated magnetic shieldings were converted into the $\delta$ chemical shifts by noting the ${ }^{1} \mathrm{H}$ absolute shielding calculated at the same level of theory in tetramethylsilane (TMS) as 31.76.

\section{Results and Discussion}

HPS has 20 different possible conformers, as can be observed from an analysis of the structure. On the basis of functional groups, these conformers can be grouped into three tautomeric classes: HP, SP, and SOP, which have 8,8 , and 4 rotamers, respectively (figures 2-4). Our computations represent that the HPs in HPS conformers are relatively more stable than the competing species (SP and SOP). Comparison of all hydrogenbonded and non-hydrogen-bonded systems at B3LYP level, in HP, SP, and SOP conformers using mean energies, reveal the following order of energetic stability (values in parentheses refer to MP2 and G2MP2, respectively):

H-bonded : HP, SP

$\Delta \mathrm{E}(\mathrm{kJ} / \mathrm{mol}): 0.0(0.0,0.0), 20.5(17.6,5.0)$
Therefore, in hydrogen bonded systems, the HP conformer is $20.5 \mathrm{~kJ} / \mathrm{mol}$ and is more stable than the SP conformer. However, the order of stability in nonhydrogen-bonded conformers is as follows:

Non-H-bonded: SP, HP, SOP

$$
\begin{gathered}
\Delta \mathrm{E}(\mathrm{kJ} / \mathrm{mol}): 24.0(19.5,6.8), 42.6(36.1,36.0), \\
50.6(26.3,26.9)
\end{gathered}
$$

\subsection{Conformation Analysis}

3.1a HP group: The structures of the HP possible conformers are presented in figure 2 . The relative energies and structural parameters were shown in tables 1 and 2 , respectively. The stability order of the different HP conformers (in $\mathrm{kJ} / \mathrm{mol}$ ) calculated at B3LYP, MP2, and G2MP2 levels, also we calculated the zero-point energy at B3LYP and MP2/6-311++G(d,p) levels of theory, and the results including ZPVE show the same stability order.

The relative energies reveal that the trans orientation of the $\mathrm{C}=\mathrm{Se}$ and $\mathrm{C}=\mathrm{C}$ bonds has greater stability than the cis orientation; this behavior results from the greater conjugation (The HP-6 structure is more stable conformer than the HP-2 conformer.). Furthermore, the HP-4 structure is more stable than the HP- 8 conformer; this stability is probably related to the repulsion between the oxygen lone pair and the $\pi$-electrons of the $\mathrm{C}=\mathrm{C}$ bond, where the trans form is less stable than the cis form. The comparison of structural parameters between the HP-1 conformers and other conformers in this group shows that the $\mathrm{C}-\mathrm{O}$ bond length decreased, while the $\mathrm{C}=\mathrm{C}$ bond length increased. These behaviors are induced by HB formation, causing an increase in the $\pi$-electron resonance of the chelated ring. This is due to the presence of a relatively strong Se...H-O hydrogen bond in the HP-1 conformer.

3.1b SP group: SP has eight conformers (figure 3), all of which are planer. A comparison of the relative energies between different SP conformers shows that SP-5 is the most stable conformer. This stability is mainly due to the formation of an $\mathrm{O} \cdots \mathrm{Se}$ bond. In addition, geometrical parameters show that in the SP5 conformer, $\mathrm{C}=\mathrm{C}$ and $\mathrm{C}=\mathrm{O}$ and $\mathrm{Se}-\mathrm{H}$ bond lengths are increased, whereas $\mathrm{C}-\mathrm{C}, \mathrm{C}-\mathrm{Se}$ bond lengths are decreased, with respect to the other SP conformers.

The relative energies reveal that the trans orientation of the $\mathrm{C}=\mathrm{O}$ and $\mathrm{C}=\mathrm{C}$ bonds has greater stability than the cis orientation (The SP-8 structure is a more stable than the SP-6 conformer). 
<smiles></smiles>

HP-l<smiles>O/C=C\C=[Se]</smiles>

HP -5<smiles>O/C=C/C=[Se]</smiles>
HP-2<smiles>O/C=C/C=[Se]</smiles>

HP-6<smiles>O/C=C\C=[Se]</smiles>

HP-3<smiles>O/C=C/C=[Se]</smiles>

HP -4<smiles>O/C=C/C=[Se]</smiles>

HP-7<smiles>O/C=C/C=[Se]</smiles>

HP-8

Figure 2. Plausible HP conformers in HPS.<smiles>O=CC=C[SeH]</smiles>

SP-1<smiles>O=C/C=C\[SeH]</smiles>

SP -5<smiles>O=C/C=C\[SeH]</smiles>

SP-2<smiles>O=C/C=C\[SeH]</smiles>

SP-3<smiles>O=C/C=C\[OH2+]</smiles>

SP-4<smiles>O=CC(C=S)C=[Se]</smiles><smiles>O=C/C=C\[SeH]</smiles>

SP-6<smiles>C=CC=O</smiles>

SP-7<smiles>O=C/C=C/[OH2+]</smiles>

SP-8

Figure 3. Plausible SP conformers in HPS.<smiles>O=CC(C=[Se])C=[Se]</smiles><smiles>O=CC1C=S=[Se]C1=[Se]</smiles><smiles>O=CC(C=[Se])C=[Se]</smiles>

Figure 4. Plausible SOP conformers in HPS.

3.1c SOP group: In hydrogen-bonded and nonhydrogen-bonded systems, SOP tautomer is less stable than HP and SP tautomers. SOP has four conformers (figure 4). Theoretical calculations show that the $\mathrm{C}=\mathrm{O}$, $\mathrm{C}=\mathrm{C}, \mathrm{C}-\mathrm{C}$, and $\mathrm{C}=$ Se bond distances in SOP conformers nearly similar (SOP-4 conformer converts to SOP-1 conformer after optimization). This means that the energy function is not sensitive with respect to bond distance changes.

\subsection{Solvent Effect}

To study the geometry and intramolecular hydrogen bond energy changes in the various HPS conformers, B3LYP/6-311++G(d,p) optimization in solution was carried out. The solvent effects were calculated using
PCM, IEFPCM, and SCIPCM models. The relative energies and geometrical parameters of HP, SP, SOP conformers are presented in tables 1-3.

The electron densities calculated at the bond critical point for the HP-1, SP-1 species are shown in table 4. The effect of solute-solvent interactions was initially taken into account by means of the SCIPCM. In this approach, the interaction between the dipole moment of the solute and the dipole induced in the surrounding medium is taken into account by enclosing the solute in a cavity defined as an isodensity surface of the molecule. This cavity is surrounded by the solvent that is considered as a uniform dielectric with a given permittivity. ${ }^{22}$

The permittivity value used $(\varepsilon=74.58)$ corresponds to that of water. The main limitation of this approach 
Table 1. Optimized energies of all possible conformations in gas phase and water solution. Values in parentheses refer to calculation at ZPVE correlation.

\begin{tabular}{lcccccc}
\hline & B3LYP & MP2 & G2MP2 & PCM & IEFPCM & SCIPCM \\
\hline HP-1 & $0(0)$ & $0(0)$ & 0 & $9.48(10.84)$ & $9.46(10.76)$ & 21.72 \\
HP-2 & $40.43(40.17)$ & $37.80(52.77)$ & 37.33 & $15.96(15.49)$ & $15.96(15.22)$ & 46.68 \\
HP-3 & $36.23(36.05)$ & $32.03(32.55)$ & 32.38 & $16.11(16.48)$ & $15.90(16.27)$ & 44.70 \\
HP-4 & $29.14(29.11)$ & $25.46(25.99)$ & 26.00 & $0.0(0.0)$ & $0.0(0.0)$ & 0.00 \\
HP-5 & $56.44(57.23)$ & $51.72(50.14)$ & 49.41 & $22.93(23.36)$ & $22.78(23.10)$ & 56.11 \\
HP-6 & $39.64(38.33)$ & $34.13(33.86)$ & 32.38 & $12.56(11.55)$ & $12.56(11.21)$ & 38.98 \\
HP-7 & $42.27(41.48)$ & $39.90(38.85)$ & 38.47 & $16.37(15.65)$ & $16.32(15.39)$ & 46.03 \\
HP-8 & $49.91(42.82)$ & $31.50(56.18)$ & 29.26 & $0.88(0.52)$ & $0.81(0.09)$ & 32.83 \\
SP-1 & $20.47(9.71)$ & $17.59(6.30)$ & 5.00 & $28.18(19.90)$ & $27.96(19.43)$ & 50.75 \\
SP-2 & $25.99(13.65)$ & $21.00(9.45)$ & 8.68 & $25.03(15.75)$ & $24.81(15.29)$ & 38.94 \\
SP-3 & $33.08(4.72)$ & $27.30(15.22)$ & 14.27 & $29.23(19.69)$ & $29.05(19.36)$ & 44.71 \\
SP-4 & $19.42(6.84)$ & $13.90(12.36)$ & 1.93 & $14.01(4.72)$ & $13.86(4.41)$ & 29.53 \\
SP-5 & $17.06(6.56)$ & $12.34(3.41)$ & 1.41 & $19.52(11.81)$ & $19.37(11.55)$ & 32.68 \\
SP-6 & $21.26(13.50)$ & $22.05(11.02)$ & 9.02 & $25.05(15.53)$ & $25.05(15.26)$ & 39.99 \\
SP-7 & $30.72(17.24)$ & $23.89(11.28)$ & 9.89 & $26.58(17.32)$ & $26.58(17.01)$ & 41.31 \\
SP-8 & $20.49(7.87)$ & $15.75(3.67)$ & 2.18 & $14.27(4.98)$ & $14.08(4.55)$ & 30.57 \\
SOP-1 & $52.51(46.87)$ & $27.56(11.55)$ & 28.44 & $53.71(51.45)$ & $53.71(51.02)$ & 65.37 \\
SOP-2 & $48.83(43.14)$ & $24.94(21.79)$ & 24.77 & $50.77(48.57)$ & $50.77(48.10)$ & 62.42 \\
SOP-3 & $50.42(45.43)$ & $26.25(23.62)$ & 27.39 & $50.76(48.75)$ & $50.76(48.49)$ & 63.30 \\
\hline
\end{tabular}

is that specific solute-solvent hydrogen bonding interactions are discarded. Hence, to estimate the possible effect of these specific interactions, we have used a direct-continuum model. ${ }^{23}$ The SCIPCM approach is applied to clusters formed by the interaction of the solute with a finite number of solvent molecules. According to the PCM model, the solute is placed in a cavity built within a solvent described as a homogeneous dielectric, which, being polarized by the solute electron density, produces a reaction field, The nonlinear electrostatic problem at the cavity surface is then solved in a rigorous and effective procedure, by using a finite element approach. ${ }^{24}$ The solvent effect, also computed in water at the IEF-PCM ${ }^{25}$ using Bonds radii scaled by 1.2 with explicit polar hydrogens,${ }^{26}$ is given by

$$
\Delta \mathrm{G}_{\mathrm{SOL}}=\mathrm{G}_{\mathrm{el}}+\mathrm{G}_{\mathrm{cav}}+\mathrm{G}_{\mathrm{dis}}+\mathrm{G}_{\mathrm{rep}}=\mathrm{G}_{\mathrm{el}}+\mathrm{G}_{\mathrm{drc}}
$$

It is necessary to mention that the hydrogen bond strength in the HPS conformers in solution phase is weaker than that in the gas phase. The conformational equilibrium on passing from the gas phase to the solution phase can also undergo remarkable changes.

The comparison of the relative energies of the dierent HPS conformers shows that hydrogen bond strength in HP-1 is more than SP-1 in solution phase.

The maximum different energy obtained on passing from the gas phase to water solution in molecules considered here are about 49.03, 33.51, $29.14 \mathrm{~kJ} / \mathrm{mol}$ and were found for the HP-8, HP-5, and HP-4, respectively, for PCM.

\subsection{AIM Analysis}

The formation of HB is associated with the appearance of a bond critical point between the hydrogen atom of donor group and acceptor atom. Popelier ${ }^{27}$ proposed a set of criteria for the specification of hydrogen bonding within the AIM formalism. Two criteria are connected with electron density, $\rho_{\mathrm{BCP}}$, and its laplacian, $\nabla^{2} \rho_{\mathrm{BCP}}$, at BCP of two hydrogen bonded atoms and the other are related to the integrated properties of the $\mathrm{H}$ atom. To have a deeper understanding of the nature of the possible hydrogen bonds in HPS conformers, a topological analysis of electronic charge density and its laplacian were performed. The property of the laplacian of the electron density, which is used to determine regions of concentration and depletion of the electron charge density, forms a basis for the classification of the atomic interactions. $^{28-30}$

Two conformers that were involved in intramolecular hydrogen bond were selected (HP-1 and SP1 conforners); the corresponding values of $\rho_{\mathrm{Bcp}}$ and $\nabla^{2} \rho_{\text {Bcp }}$ for these conformers are presented in table 4 . Comparison between the laplacian of HP-1 and SP-1 in solution phase (For $\mathrm{Se}-\mathrm{H}$ and $\mathrm{O}-\mathrm{H}$ bonding) showed that $\nabla^{2} \rho_{\mathrm{BCP}}$ for the SP-1 conformer is higher than the corresponding value for HP-1. But $\rho_{\mathrm{BCP}}$ for the HP-1 conformer is higher than the corresponding value for SP-1.

As a consequence, the strength of the hydrogen bond in HP-1 is greater than in SP-1 in both the phases. The following $\mathrm{BCP}$ are considered and analyzed in 


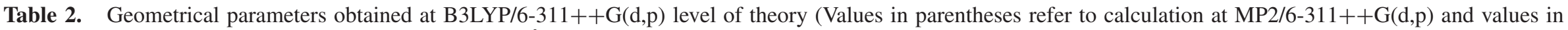

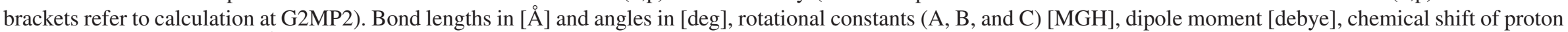
$[\mathrm{ppm}]$, and frequencies $\left[\mathrm{cm}^{-1}\right]$ are included for all conformers ( $\mathrm{X}$ and $\mathrm{Y}=\mathrm{Se}$ or $\mathrm{O}$ atoms).

\begin{tabular}{|c|c|c|c|c|c|c|c|c|c|c|c|c|}
\hline & $\mathrm{CO}$ & $\mathrm{CC}$ & $\mathrm{CC}$ & $\mathrm{CSe}$ & $\mathrm{X}-\mathrm{H}$ & A & B & $\mathrm{C}$ & & $v \mathrm{X}-\mathrm{H}$ & $\gamma \mathrm{X}-\mathrm{H})$ & $\mu$ \\
\hline HP-1 & $1.310(1.318)[1.323]$ & $1.409(1.422)[1.416]$ & $1.376(1.375)[1.372]$ & $1.816(1.796)[1.787]$ & $1.005(1.796)[1.005]$ & $7.13(7.12)$ & $2.02(2.03)$ & $1.57(1.58)$ & 15.348 & 2969.85 & 822.63 & 2.84 \\
\hline HP-2 & $1.339(1.318)[1.347]$ & $1.432(1.422)[1.440]$ & $1.354(1.375)[1.352]$ & $1.794(1.777)[1.768]$ & $0.967(0.996)[0.976]$ & $12.59(12.41)$ & $1.22(1.23)$ & $1.11(1.12)$ & 4.6244 & 3778.82 & 553.38 & 4.29 \\
\hline HP-3 & $1.341(1.347)[-]$ & $1.421(1.434)[-]$ & $1.360(1.355)[-]$ & $1.789(1.777)[-]$ & $0.966(0.965)[-]$ & 19.24(19.04) & $1.076(1.08)$ & $1.019(1.02)$ & 6.5868 & 3783.08 & 561.29 & 2.88 \\
\hline HP-4 & $1.342(1.347)[1.349]$ & $1.423(1.436)[1.429]$ & $1.355(1.362)[1.353]$ & $1.789(1.775)[1.766]$ & $1.341(0.965)[0.976]$ & $32.30(.32 .10)$ & $0.94(0.95)$ & $0.92(0.92)$ & 4.1873 & 3786.38 & 544 & 3.67 \\
\hline HP-5 & $1.339(1.339)[1.359]$ & $1.429(1.429)[1.435]$ & $1.357(1.357)[1.356]$ & $1.792(1.792)[1.771]$ & $0.963(0.963)[0.973]$ & $7.22(7.22)$ & $1.82(1.82)$ & $1.45(1.45)$ & 4.596 & 2823.73 & 508.22 & 5.17 \\
\hline HP-6 & $1.35(1.356)[1.359]$ & $1.42(1.357)[1.431]$ & $1.354(1.438)[1.352]$ & $1.789(1.776)[1.767]$ & $0.96(0.960)$ & 19.12( & .09) & 04) & 12.553 & 38 & 456.97 & 5.79 \\
\hline HP-7 & $1.344(1.356)[1.352]$ & $1.431(1.357)[1.438]$ & $1.351(1.438)$ & $1.796(1.776)[1.771]$ & $0.96(0.961)[0.972]$ & $12.46(12.33)$ & $1.23(1.24)$ & $1.12(1.12)$ & 4.6 & 383 & & 3.78 \\
\hline HP-8 & $1.43,(1.352)[1.354]$ & $1.54,(1.355)[1.428]$ & $1.3531,(1.435)[1.352]$ & $1.59(1.776)[1.767]$ & $0.96(0.961)[0.971]$ & $29.55(33.23)$ & $1.006(0.95)$ & $0.97(0.92)$ & 2.7084 & 3878.49 & 130.56 & 6.11 \\
\hline SP-1 & $1.228(1.228)[1.228]$ & $1.466(1.465)[1.473]$ & $1.360(1.368)[1.345]$ & $1.877(1.877)[1.872]$ & $1.462(1.4612)[1.483]$ & $7.208(7.19)$ & $1.89(1.88)$ & $1.501(1.49)$ & 9.492 & 2310.42 & 487 & 2.52 \\
\hline SP-2 & $1.224(1.221)[1.228]$ & $1.480(1.48)[1.473]$ & & $(1.88)[1.872]$ & & 19.3 & & & & & & 3.47 \\
\hline SP-3 & $1.214(1.222)[1.229]$ & $1.474(1.467)[1.461]$ & $342(1354$ & $1887(18$ & $1473(145$ & 1217 & 1.21 & 1.10 & $5 .($ & 238 & 374.34 & 3.37 \\
\hline SP-4 & $1.213(1.213)[1.227]$ & .465)[1.462] & $342)[$ & 77] & $1.473(1.473)[1.483]$ & $32.84(32.45)$ & $0.94(0.94)$ & $0.91(0.92)$ & 3.8917 & 2357.35 & 311.28 & 3.62 \\
\hline SP-5 & $1.223(1.229)[1.238]$ & $1.455(1.462)[1.452]$ & $1.350(1.357)[1.352]$ & $1.888(1.883)[1.872]$ & $1.484(1.468)[1.494]$ & $19.77(7.08)$ & $1.07(1.08)$ & $1.02(3.72)$ & 3.984 & 2256.91 & 562.39 & 3.72 \\
\hline SP-6 & $1.214(1.221)[1.228]$ & $1.474(1.480)[1.472]$ & $1.342(1.35)[1.345]$ & $1.893(1.887)[1.879]$ & $1.471(1.458)[1.481]$ & 19.77(19.47) & $1.075(1.08)$ & $1.02(1.024)$ & 3.505 & 2383.99 & 250.48 & 2.85 \\
\hline SP-7 & $1.213(1.221)[1.222]$ & $1.463(1.468)[1.463]$ & $1.344(1.352)[1.347]$ & $1.911(1.904)[1.897]$ & $1.471(1.458)[1.481]$ & 10.97(10.77) & $1.31(1.32)$ & $1.17(1.18)$ & 3.4189 & 2374.22 & 381.99 & 4.37 \\
\hline SP-8 & $1.213(1.220)[1.227]$ & $1.54(1.470)[1.464]$ & $1.355(1.350)[1.345]$ & $1.897(1.891)[1.883]$ & $1.09(1.458)[1.481]$ & $31.73(31.42)$ & $0.95(0.95)$ & $0.92(0.92)$ & 3.4827 & 2377.41 & 306.1 & 4.36 \\
\hline SOP-1 & $1.258(1.214)[1.220]$ & $1.519(1.61)[1.514]$ & $1.494(1.503)[1.496]$ & & - & & & & 10.143 & - & - & 3.1 \\
\hline & $1.203(1.213)[1.221]$ & $1.522(1.213)[1.513]$ & $1.492(1.520)[1.492]$ & $1.763(1.760)[1.751]$ & - & $13.80(11.60)$ & & 111 (1 & 9.97 & - & - & 2.85 \\
\hline SOP-3 & $1.258(1.214)[1.219]$ & $1.527(1.516)[1.518]$ & $1.493(1.503)[1.496]$ & $1.764(1.764)[1.753]$ & - & $14.36(12.33)$ & $1.09(1.15)$ & $1.06(1.11)$ & 10.436 & - & - & 3.47 \\
\hline
\end{tabular}


Table 3. Geometrical parameters obtained in water solution at the PCM method. (Values in parentheses refer to calculation at the IEF-PCM method and values in brackets refer to calculation at the SCI-PCM method), Bond lengths in [̊̊], and angles in [deg], rotational constants [MGH], dipole moment [debye], chemical shift of proton [ppm] and frequencies $\left[\mathrm{cm}^{-1}\right]$ are included for all conformers (X and $\mathrm{Y}=\mathrm{Se}$ or $\mathrm{O}$ atoms).

\begin{tabular}{|c|c|c|c|c|c|c|c|c|c|c|c|c|}
\hline & $\mathrm{CO}$ & $\mathrm{CC}$ & $\mathrm{CC}$ & $\mathrm{CSe}$ & $\mathrm{X}-\mathrm{H}$ & A & B & $\mathrm{C}$ & $\delta$ & $v \mathrm{X}-\mathrm{H}$ & $\gamma \mathrm{X}-\mathrm{H})$ & $\mu$ \\
\hline HP-1 & $1.31(1.313)[1.313]$ & $376(1.378)[1.378]$ & $409(1.405)[1.405]$ & $1.816(1.825)[1.823]$ & $1.005(1.003)[1.004]$ & $7.09(7.09)$ & $1.98(1.98)$ & $1.55(1.55)$ & 12.459 & 3011.07 & 765.6 & 4.42 \\
\hline HP-2 & $1.339(1.32)[1.321]$ & $1.354(1.366)[1.361]$ & $433(1.415)[1.422]$ & $1.818(1.818)[1.808]$ & $0.995(0.99)[0.969]$ & $12.53(12.53)$ & $1.21(1.21)$ & $1.10(1.10)$ & 8.514 & 3190.25 & 606.6 & 7.43 \\
\hline HP-3 & $1.324(1.324)[1.331]$ & $1.372(1.372)[1.336]$ & $1.407(1.408)[1.414]$ & $1.81(1.810)[1.801]$ & $0.989(0.989)[0.968]$ & $1.05(12.25)$ & $1.05(1.21)$ & $1.00(1.00)$ & 8.707 & 3289.83 & 564.5 & 6.11 \\
\hline HP-4 & $1.321(1.321)[1.328]$ & $1.369(1.369)[1.368]$ & $1.345(1.406)[1.413]$ & $1.789(1.814)[1.803]$ & $0.995(0.995)[0.969]$ & $33.12(33.12)$ & $0.94(0.94)$ & $0.91(0.91)$ & 7.387 & 3181.71 & 614.5 & 7.43 \\
\hline HP-5 & $1.321,(1.322)[1.325]$ & $70(1.370)[1.366]$ & 413(1.413)[1.418] & $1.816(1.816)[1.806]$ & $0.991(0.991)[0.967]$ & 7.24(7.24) & $1.78(1.78)$ & $1.43(1.43)$ & 7.850 & 3242.33 & 578.8 & 8.65 \\
\hline HP-6 & $1(1.351)[1.325]$ & $51(1.351)[1.325]$ & $25(1.425)[1.418]$ & $88(1.788)[1.806]$ & $0.961(0.962)[0.967]$ & 19.12(19.12) & $1.08(1.08)$ & $3(1.03)$ & 2.628 & & 409.7 & 6.29 \\
\hline HP-7 & $3(1323)$ & $.329]$ & 20] & 99] & 0.9 & 12.5 & 1.21( & 1.1 & 7.656 & 324 & 526.7 & 6.95 \\
\hline HP-8 & $1.32(1.323)[1.330]$ & $1.32(1.323)[1.330]$ & $1.405(1.67)[1.362]$ & $1.814(1.814)[1.804]$ & $0.99(0.990)[0.966]$ & $34.16(34.16)$ & $0.94(0.94)$ & $0.92(0.92)$ & 5.237 & 3256.08 & 510.6 & 10.2 \\
\hline SP-1 & $1.232(1.232)[1.229]$ & $1.35(1.354)[1.353]$ & $1.453(1.453)[1.454]$ & $1.883(1.883)[1.883]$ & $1.473(1.473)[1.475]$ & $7.23(7.23)$ & $1.85(1.85)$ & $1.47(1.47)$ & 8.369 & & 450 & 3.68 \\
\hline SP-2 & $1.227(1.227)[1.223]$ & $1.347(1.347)[1.346]$ & $1.463(1.462)[1.465]$ & $1.883(1.883)[1.884]$ & $1.473(1.473)[1.473]$ & $19.43(19.44)$ & $1.07(1.07)$ & $1.01(1.01)$ & & 2388.51 & 326.9 & 5.06 \\
\hline SP-3 & 1.228 & & & & & & & & 4.9 & & & 5.11 \\
\hline SP-4 & 1.22 & 50] & .452)[ & 86] & $1.472(1.472)$ & $32.59(32.59)$ & $0.94(0.94)$ & $0.92(0.92)$ & 3.925 & 2386.5 & 327.9 & 5.48 \\
\hline SP-5 & $1.232(1.232)[1.223]$ & $1.352(1.352)[1.350]$ & $1.450(1.450)[1.453]$ & $1.888(1.889)[1.896]$ & $1.477(1.477)[1.469]$ & $7.11(7.11)$ & $2.14(2.14)$ & $1.64(1.64)$ & 4.272 & 2359.43 & 479.9 & 4.85 \\
\hline SP-6 & $1.227(1.227)[1.222]$ & $1.348(1.347)[1.345]$ & $1.462(1.462)[1.466]$ & $1.888(1.888)[1.889]$ & $1.469(1.470)[1.469]$ & 19.94(19.94) & $1.07(1.07)$ & $1.01(1.01)$ & 4.214 & 2420.06 & 264.6 & 4.28 \\
\hline SP-7 & $1.227(1.226)[1.222]$ & $1.227(1.226)[1.348]$ & $1.227(1.226)[1.454]$ & $1.227(1.226)[1.904]$ & $1.227(1.226)[1.469]$ & 11.19(11.19) & $1.29(1.29)$ & $1.16(1.16)$ & 3.498 & 2412.54 & 382.7 & 6.49 \\
\hline SP-8 & $1.228(1.227)[1.227]$ & $1.348(1.348)[1.348]$ & $1.452(1.451)[1.451]$ & $1.890(1.890)[1.890]$ & $1.470(1.470)[1.470]$ & $31.63(31.63)$ & $0.95(0.93)$ & $1.55(1.55)$ & 4.300 & 2408.51 & 321.3 & 6.56 \\
\hline SOP-1 & $1.212(1.212)[1.209]$ & $1.512(1.512)[1.514]$ & $1.491(1.491)[1.492]$ & $1.772(1.772)[1.771]$ & - & & & $1.33(1.33)$ & 12.915 & - & - & 4.56 \\
\hline SOP-2 & & $1.516(1.516)[1.489]$ & $1.488(1.488)[1.517$ & $1.768(1.768)[1.768]$ & - & & & $1.14(1.21)$ & 12.690 & - & - & 4.33 \\
\hline SOP-3 & $1.209(1.209)[1.206]$ & $1.521(1.521)[1.522]$ & $1.49(1.490)[1.491]$ & $1.77(1.77)[1.768]$ & - & 14.63(1.08) & $1.08(1.08)$ & $1.05(1.05)$ & 9.564 & - & - & 3.96 \\
\hline
\end{tabular}


Table 4. Topological and geometries parameters of chelated and open ring structures and second-order perturbation energy in HP-1 and SP-1 in gas phase and water solution ( $\mathrm{X}$ and $\mathrm{Y}=\mathrm{Se}$ or $\mathrm{O}$ atoms).

\begin{tabular}{lccccc}
\hline & \multicolumn{2}{c}{ Gas } & & \multicolumn{2}{c}{ Water } \\
\cline { 2 - 3 } \cline { 5 - 6 } Parameters & HP-1 & SP-1 & & HP-1 & SP-1 \\
\hline Y $\cdots H$ & 2.151 & 1.997 & & 2.155 & 2.081 \\
O $\cdots$ Se & 3.075 & 3.204 & & 3.075 & 3.473 \\
OHSe & 151.4 & 133.7 & & 151.4 & 131.3 \\
$\rho_{\mathrm{Y}} \ldots \mathrm{H}$ & 0.0399 & 0.027 & & 0.0347 & 0.0228 \\
$\nabla^{2} \rho_{\mathrm{Y}} \ldots \mathrm{H}$ & 0.0457 & 0.085 & & 0.0471 & 0.0723 \\
$\rho_{\mathrm{RCP}}$ & 0.0147 & 0.014 & & 0.011 & 0.0103 \\
$\nabla^{2} \rho_{\mathrm{RCP}}$ & -0.02 & -40.055 & & 0.0589 & 0.0537 \\
$\mathrm{G}$ & 0.0209 & 0.021 & & 0.0184 & 0.0173 \\
$\mathrm{~V}$ & 0.0305 & 0.021 & & 0.0251 & 0.0166 \\
$\mathrm{H}$ & 0.0096 & $6 \mathrm{E}-05$ & & 0.0066 & 0.0007 \\
$\mathrm{E}_{\mathrm{HB}}^{*}$ & -40.08 & -27.73 & & -32.981 & -21.729 \\
$\mathrm{E}_{\mathrm{HB}}$ & 56.44 & -3.41 & & 13.45 & -8.66 \\
$\mathrm{LP} \rightarrow \sigma_{\mathrm{X}}^{*}-\mathrm{H}$ & 31.84 & 7.22 & & 24.24 & 5.25 \\
$\mathrm{O} . \mathrm{N}_{(\mathrm{LP})}$ & 1.834 & 1.871 & & 1.8661 & 1.8879 \\
$\mathrm{O} . \mathrm{N} .\left(\sigma_{\mathrm{XH}}^{*}\right)$ & 0.1239 & 0.036 & & 0.0984 & 0.0281 \\
$\Delta(\mathrm{H}-\mathrm{L})$ & 0.124 & 0.159 & & 0.124 & 0.162 \\
$\mathrm{E}_{\mathrm{BR}}$ & 0.0386 & 0.021 & & 0.0326 & 0.018 \\
\hline
\end{tabular}

this study: electron density at $\mathrm{BCP}\left(\rho_{\mathrm{BCP}}\right)$, its lapla$\operatorname{cian}\left(\nabla^{2} \rho_{\mathrm{BCP}}\right)$, the total electron energy density $\left(\mathrm{H}_{\mathrm{BCP}}\right)$, and its component: the kinetic electron energy density $\left(\mathrm{G}_{\mathrm{BCP}}\right)$ and the potential electron density $\left(\mathrm{V}_{\mathrm{BCP}}\right)$. Some authors claim that if the laplacian is positive but the $\mathrm{H}_{\mathrm{BCP}}$ value $\left(\mathrm{H}_{\mathrm{BCP}}=\mathrm{G}_{\mathrm{BCP}}+\mathrm{V}_{\mathrm{BCP}}\right)$ is negative, then the interaction is partially covalent in nature ${ }^{19}$ (value of $\mathrm{G}$, $\mathrm{H}, \mathrm{V}$ were shown in table 4).

\subsection{NBO Analysis}

The NBO analyses ${ }^{13}$ were applied to evaluate the hydrogen-bond strength in the HP-1 and SP-1 conformers. Table 4 shows some of the significant donor-acceptor interactions and their second-order perturbation energies $\mathrm{E}^{(2)}$ (calculated at B3LYP/6-311 $++\mathrm{G}(\mathrm{d}, \mathrm{p})$ level of theory). In the NBO analysis of the hydrogen bond system, the charge transfer between the lone pairs of proton acceptor and anti-bonds of the proton donor is the most important parameter. The NBO occupation numbers for the $\sigma^{*} \mathrm{XH}$ anti-bonds, $\mathrm{Y}$ lone pairs $(\mathrm{nY})$, and orbital energy (E) are reported in table 4. In NBO analysis of HB systems, the charge transfer between the lone pairs of proton acceptor and antibonds of proton donor is most significant. The donoracceptor interaction and their second-order perturbation stabilization energies $\mathrm{E}^{(2)}$ (calculated at B3LYP/6-311 $++\mathrm{G}(\mathrm{d}, \mathrm{p})$ level of theory) for the chelated rings of HP1 and SP-1 are presented in table 4. As a consequence, the similar tend strength with the NBO analysis show that in chelated structures of HP-1conformer, two lone pairs of Selenium atom participate as donor and the $\sigma^{*}(\mathrm{O}-\mathrm{H})$ anti-bond as acceptor in strong intramolecular charge transfer interaction. Also in SP-1, two lone pairs of $\mathrm{O}$ atom participate as donor and the $\sigma^{*}(\mathrm{Se}-$ $\mathrm{H})$ anti-bonds as acceptor in strong intramolecular charge transfer interactions. The charge transfer energy increases on going from SP-1 to HP-1 in solution phase. This order again supports the previous results about the intramolecular HB strength of HP-1 and SP-1.

\subsection{Rotational constants, dipole moments and NMR}

The rotational constants and dipole moments of the conformers calculated at the B3LYP and the MP2/6$311++\mathrm{G}(\mathrm{d}, \mathrm{p})$ levels of theory are presented in tables 2 and 3. The calculated rotational constants of the HPS conformers continuously decrease from 31.73 to 7.13 $\mathrm{cm}^{-1}$, while the dipole moments continuously increase from 2.518 to 6.107 . Furthermore, with increasing strength of hydrogen bonding we expected that rotational constants decrease. As an example, HP-1 has a stronger hydrogen bonding than SP-1 conformer. Furthermore, it has a lower rotational constant and higher dipole moment. The agreement between MP2 and B3LYP optimized values is fairly good and the corresponding rotational constants differ by $0.0103 \%$ on average.

The GIAO method is one of the most common approaches for calculating nuclear magnetic shielding tensors. The ${ }^{1} \mathrm{H}$ NMR isotropic shielding was calculated using the GIAO method..$^{21,31}$ Chemical shifts were calculated as $\delta=\sigma_{\text {ref }}-\sigma$, where $\sigma_{\text {ref }}$ was the computed shielding constant of TMS. The effect of solvent on the theoretical ${ }^{1} \mathrm{H}$ NMR parameters was included using the default model PCM provided by Gaussian 03 .

The hydrogen-bonded structure, the relationship between the hydrogen bond length and ${ }^{1} \mathrm{H}$ NMR chemical shift were measured. ${ }^{1} \mathrm{H}$ chemical shifts provide useful information about the hydrogen-bonded structure. The ${ }^{1} \mathrm{H}$ chemical shifts for all hydrogen-bonded systems in all conformers were calculated by the GIAO method at the B3LYP/6-311G++(d,p) level (tables 2 and 3). The results confirm that the strengthening of the hydrogen bond causes ${ }^{1} \mathrm{H}$ chemical shift, as $\mathrm{H}$ moves to down fields.

\section{Conclusion}

A theoretical study of 20 possible conformers of HPS has been carried out by means of ab initio (MP2/6$311++\mathrm{G}(\mathrm{d}, \mathrm{p})$ and G2MP2) and DFT (B3LYP/6-311+ 
$+\mathrm{G}(\mathrm{d}, \mathrm{p}))$ calculations and harmonic vibrational frequencies were also calculated to confirm the nature of the stationary points found and to discuss the ZPVE correction. The rotational constants, dipole moments, NMR, NBO, and AIM analyses were used to discuss the origin of conformational preference and hydrogen bond strength. Theoretical calculations showed that the HP1 is the most stable conformer of HPS in the gas phase and the HP-4 is the most stable conformer of HPS in solution. We conclude that the hydrogen bond strength in the HP conformer (Se...H-O) in solution is stronger than in the gas phase. Our results also showed that ZPVE correction does not have any significant effect on the stability order of these conformers.

\section{References}

1. Krief A and Hevesi L 1988 In Organoselenium Chemistry I: Functional group transformations (Berlin: Springer-Verlag)

2. Patai S and Rappoport Z 1986 In The chemistry of organic selenium and tellurium compounds (Chichester: John Wiley \& Sons)

3. Paulmier C and Baldwin J E 1986 In Selenium reagents and intermediates in organic synthesis (Oxford: Pergamon)

4. Freudendahl D M, Santoro S, Shahzad S A, Santi C and Wirth T 2009 Angew. Chem. 488409

5. Raissi H, Yoosefian M and Mollania F 2012 Comput. Theor. Chem. 99668

6. Raissi H, Yoosefian M and Mollania F 2012 Int. J. Quant. Chem. 1122782

7. Raissi H, Yoosefian M and Khoshkhou S 2012 Comput. Theor. Chem. 9831

8. Yoosefian M, Raissi H, Nadim E S, Farzad F, Fazli M, Karimzade E and Nowroozi A 2011 Int. J. Quant. Chem. 1113505

9. Raissi H, Yoosefian M, Mollania F, Farzad F and Nowroozi A R 2011 Comput. Theor. Chem. 966299
10. Raissi H, Jalbout A, Nasseria M, Yoosefian M, Ghiassi $\mathrm{H}$ and Hameed A 2008 Int. J. Quant. Chem. 1081444

11. Kovačević B, Glasovac Z and Maksiĉ Z B 2002 J. Phys. Org. Chem. 15765

12. Raissi H, Yoosefian M, Mollania F and Farzad F $2012 J$. Theor. Comput. Chem. 11925

13. Reed A E, Curtiss L A and Weinhold F 1988 Chem. Rev. 88899

14. Bader R F 1990 Atoms in molecules (Wiley Online Library)

15. Frisch M, Trucks G, Schlegel H, Scuseria G, Robb M, Cheeseman J, Montgomery Jr. J, Vreven T, Kudin K and Burant J, Gaussian 03 Gaussian. Inc.: Wallingford CT (2004)

16. Becke A D 1993 J. Chem. Phys. 985648

17. Møller C and Plesset M S 1934 Phys. Rev. 46618

18. Bader R F 1998 J. Phys. Chem. A 1027314

19. Glendening ED, Reed AE, Carpenter J E and Weinhold F 2003 NBO (Version 3.1) Gaussian Inc, Pittsburg, PA

20. Tomasi J, Cammi R, Mennucci B, Cappelli C and Corni S 2002 Phys. Chem. Chem. Phys. 45697

21. Wolinski K, Hinton J F and Pulay P 1990 J. Ame. Chem. Soc. 1128251

22. Tomasi J and Persico M 1994 Chem. Rev. 942027

23. Pardo L, Osman R, Weinstein $\mathrm{H}$ and Rabinowitz J R 1993 J. Ame. Chem. Soc. 1158263

24. Miertuš S, Scrocco E and Tomasi J 1981 Chem. Phys. 55117

25. Carcabal P, Snoek L and Van Mourik T 2005 Mol. Phys 1031633

26. Bondi A 1964 J. Phys. Chem. 68441

27. Popelier P L A and Bader R F W 1992 Chem. Phys. Lett. 189542

28. Gilli P, Bertolasi V, Ferretti V and Gilli G 2000 J. Ame. Chem. Soc. 12210405

29. Raissi H, Yoosefian M, Mollania F and Khoshkhou S 2013 Struct. Chem. 24123

30. Gilli P, Bertolasi V, Pretto L, Lycfika A and Gilli G 2002 J. Ame. Chem. Soc. 12413554

31. Raissi H, Yoosefian M, Hajizadeh A, Js Imampour, Karimi M and Farzad F 2012 Bullet. Chem. Soc. Jap. 8587 